\title{
RFID TECHNNOLOGY - NEW CHALLENGE FOR MANUFACTURING AND LOGISTICS CENTERS
}

\author{
PhD Beata Skowron-Grabowska, Management Faculty, Czestochowa University of Technology, e- \\ mail:beatas@zim.pcz.pl
}

\begin{abstract}
ABSTACT: RFID technology can be exploited in newly developed logistics centers in Poland as well. The Radio frequency identification (RFID) has been recognized as one of the greatest technologies implemented by enterprises in different branches. Constantly increasing number of enterprises, which are making use of RFID technology to improve their efficiency of manufacturing goods, functioning as well as to achieve a competitive advantage on the market, shows the great necessity of large changes. One of the fields where RFID can be used is logistics centers. There are projects that implement RFID into logistics centers. Such projects start with a study of what kinds of needs are in the market, and proceeds to the development of concept as well as project determines what the new systems and hardware requirements will be to translate the concept of logistics centers with RFID systems to an actual infrastructure. Conclusion is that RFID will be more universally diffused and assimilated into everyday life in the future.
\end{abstract}

Keywords: RFID, logistics centre, project

JEL Codes: $M 10$

\section{What is RFID?}

RFID is a technology for the automatic identification by radio of physical objects such as industrial containers, palettes, individual products and also people. The identification event takes place over transponders located in or on the respective objects, which can be addressed without physical contact, over the so-called "air interface', by the antenna on a scanner device. Typical areas of application for RFID lie, adjacent to classics such as animal identification or access control systems, above all in supply chain management, where the technology makes possible simplified goods turnover, automatic stock control in the storeroom, the sales floor, theft protection, product tracking etc. ${ }^{1}$

Above description of RFID technology means standard projects. There can be situations when it is possible to find new solutions. The biggest potential lies in ultra high-frequency (UHF) passive RFIDs which function without battery and a very small-sized antenna can be used for item tracking, especially useful for different kinds of logistics centers, especially those built for global companies. Once all goods are attached with RFID tags, their site can be tracked automatically by radio readers, which give complete inventory visibility as well as efficient management of logistics centre. $^{2}$

\footnotetext{
${ }^{1}$ F. Thiesse RFID, privacy and the perception of risk: A strategic framework, Journal o Strategic Information Systems 16 (2007) 214-232, 215-216

${ }^{2}$ N.C. Wu, M.A. Nystrom, T.R. Lin, H.C. Yu Challenges to global RFID adoption Technovation 26 (2006) 1317-1323, p. 1317
} 


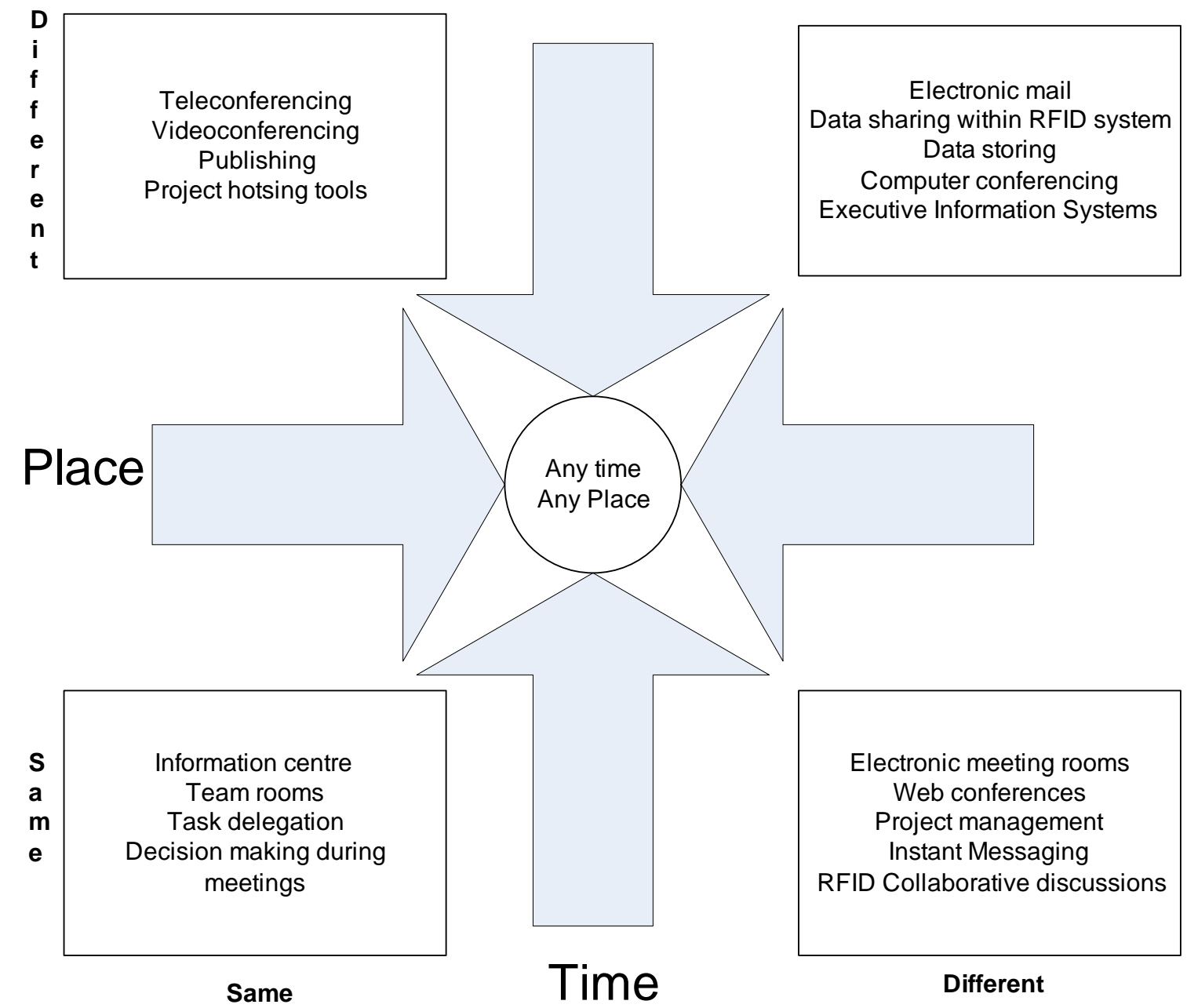

Fig. no. 1 Implementation of RFID in an organization

Source: based on M. Attaran, Collaborative computing: a new management strategy for increasing productivity and building a better business, VOL. 8 NO. 6 2007, pp. 387-393, Emerald Group Publishing Limited, ISSN 1751-5637 BUSINESS STRATEGY SERIES, p. 388

In order to implement RFID in logistics centers it is necessary prepare a project. Before first step is taken there must be many discussions with use of different means as one can observe in figure 1 . Some of them are easy to organize such as team rooms while some of them require more work and equipment such as videoconferencing.

\section{Logistics centre - modern way of distribution}

A logistics centre is a special place, where supply meets demand for different logistics services and products. One can show differences between functioning of a warehouse and logistics centre. The warehouses provide physical expression of the need to store large inventories, the main object of traditional retailing. The logistics center, in opposite, shapes the network of connections between suppliers, producers and retailers. In this place it is possible to control processes of incoming goods efficiently, guarantee that incoming deliveries match purchase orders, and route orders for shipment to the correct store. ${ }^{3}$

\footnotetext{
${ }^{3}$ F. H. Abernathy, J. T. Dunlop, J. H. Hammond, D. Weil, Retailing and supply chains in the information age, Technology in Society 22 (2000) 5-31, Elsevier, p. 11
} 


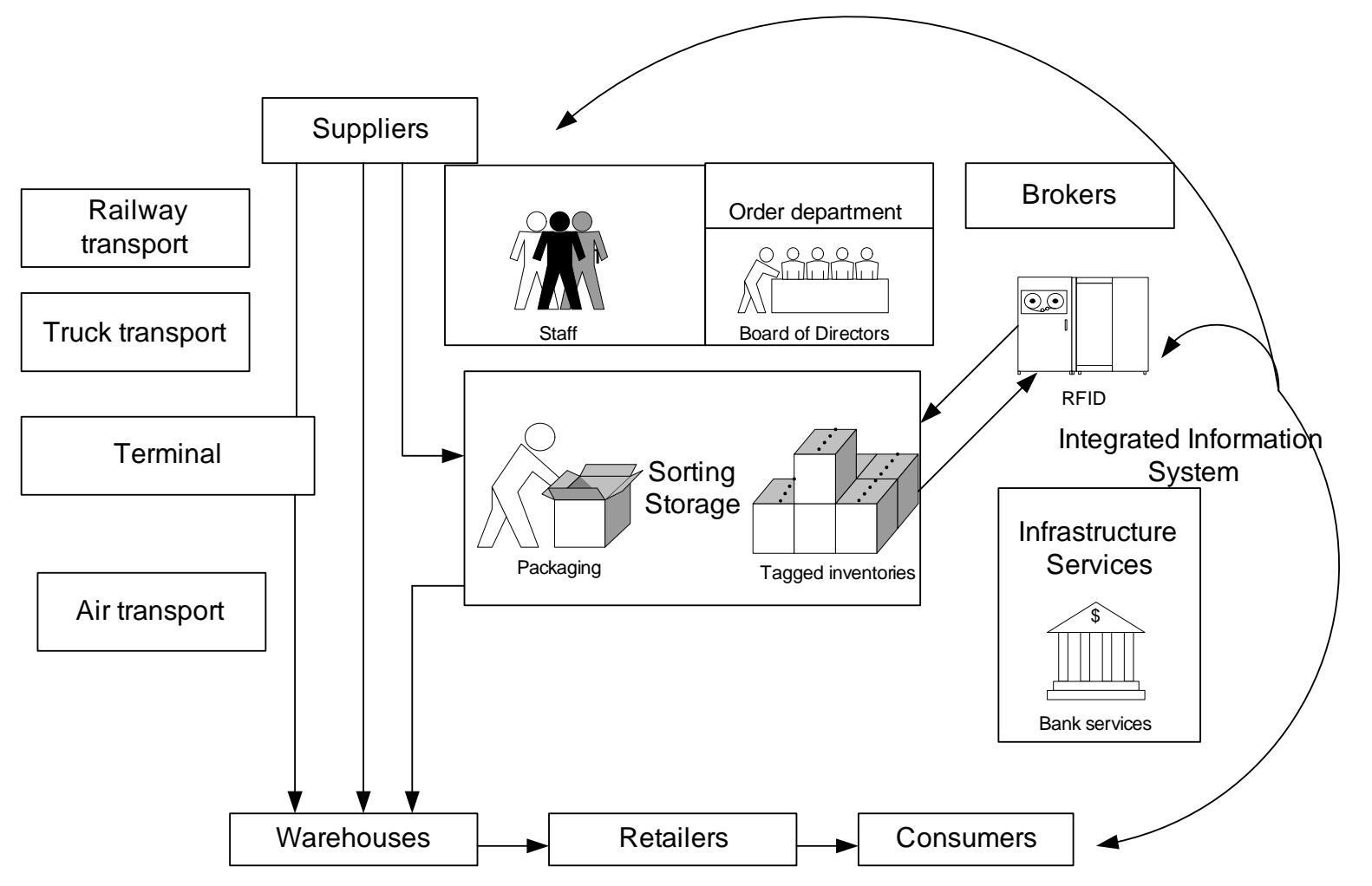

Fig. no. 2 Logistics centre with implemented RFID system

Source: Author's own elaboration based on S. Abt, Zarzadzanie logistyczne w przedsiebiorstwie, PWE, Warszawa 1998, p. 211

The example how the logistics center look like is shown in figure 2. Transportation, storage, packaging, labeling and other functions are concentrated in one place. Localization of such centers helps to coordinate work of all market participants.

Development of logistics centers is strictly connected with development of new multimodal technologies, which offer an appropriate computer structure, adjusted to many transport branches. The basic rule accepted in the whole world in designing and locating logistics centers is to relate them directly with at least two transport branches.

There are many newly built logistics centers all over Poland. Most of these centers are situated near large Polish cities like: Warsaw, Szczecin, Gdansk, Wroclaw, Poznan, Gliwice and others. The most popular elements of Polish logistics centers are terminals for building materials, agricultural products, small products, liquid fuels and gases as well as container terminal. There are special buildings within the area of logistics centre where custom clearance take place. Some of them are trying to implement new information systems while others are still learning to put into actions new services.

\section{RFID project implemented in logistics centre}

First step in executing RFID system is refining the process and conducting team training. During this step there must be identification of participants and roles for each step in the process. The project leader determines who is needed, how much of their time will be necessary, and when. Another task in this step is to refine the process for the RFID business case as well as to review and finalize the objectives and deliverables. Examples of objectives include establishing a 
recommended plan for RFID deployment and assessing the business risks of RFID deployment. Examples of deliverables include an executive level presentation and an implementation roadmap. Establish consensus on the business case methodology and assumptions

Second step in developing RFID project is to determine scope and assumption. All RFID tagging is done at the unit, case, and pallet level. There is a need to establish early in logistic centre case what level of item will be tagged. For most retail consumer packaged-goods manufacturers, tagging occurs at the case and pallet level. For others, it is necessary to tag at the unit, case, and pallet level. At this point in the process, the level which is determined is like a hypothesis. One can prove or disprove these hypothesis during the alignment of drivers, strategies, and enablers in third step. ${ }^{4}$

In third step one can determine drivers, strategies and enablers. This step can be easily explained on an example. First of all it is necessary to define expectations collaboration with business observance: logistics centre and requirements with associates modify an influence on trading partners in different ways. Logistics centre benefits indirectly from usage of RFID data of trading partners as well. Next stage in third step is maintain compliance RFID-tagged items at the unit, with government case, and pallet level regulations.

Fourth step is identification and assess business processes and interfaces. In this step, one can develop a high-level model of company's business processes, which will help someone determines how RFID will impact those processes and the associated information system applications.

Fifth step is identification complementary or competing business initiatives. Here, it is necessary to establish one of business case and implementation "radar screens" by identifying what can be leveraged for success and what needs to be closely monitored as competition for the RFID initiative.

Sixth step deals with identification of strategic and economic benefits for the logistics centre. This step is among the more time-consuming in the process . The idea is to summarize the strategic impact on logistics centre' operations.

Seventh step means development of investment requirements. In case of logistics centre businesses are not complete without information about what this specific kind of company requirements to invest in order to get RFID up and running. There are needs to approximate the costs of hardware, software, implementation, integration, training, and support potential profits of RFID enablement.

Eighth step is connected with development and an implementation road map. In this step, one must decide about the implementation plan due to understand the timing of the benefits and costs for the logistics centre.

The last ninth step in the business case is quantifying the overall project and developing a framework for presenting it. ${ }^{5}$

After preparing RFID project in the logistics centre it is necessary to choose how the RFID information network will work in cooperation with other business partners. As a product flows from its manufacturer to logistics centre and then to retailers, each of these parties captures its tracking information. How is the tracking information in the logistics centre look like in comparison to the tracking information originally supplied by the manufacturers and then complemented by the retailers? In the situations like these it is necessary to use the Object Naming Service (ONS) and the EPCIS (Electronic Product Code Information System).

The ONS can be on a local network or on the internet, and it is similar to the domain name service that associates an internet provider address with a domain name. The ONS serves as a directory that locates the server containing the information for the item being scanned. ${ }^{6}$

4 P. J. Sweeney, RFID for Dummies, Wiley Publishing, Inc., Indianapolis, Indiana, USA, 2005, p. 271-275

${ }^{5}$ P. J. Sweeney, RFID for Dummies, Wiley Publishing, Inc., Indianapolis, Indiana, USA, 2005, p. 276-287 


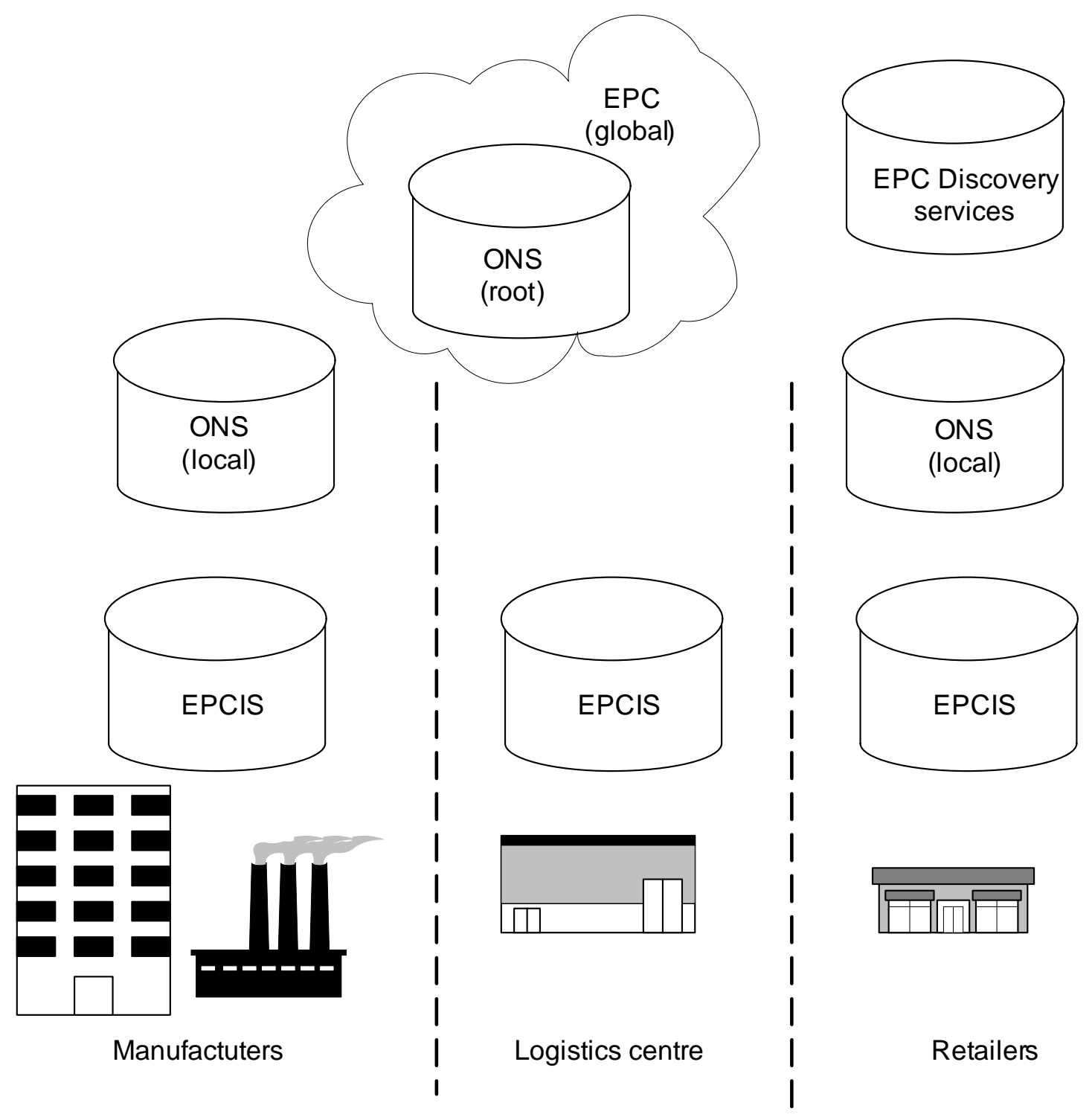

Fig. no. 3 The RFID information network connecting logistics centre with manufactures and retailers

Source: H. Bhatt, B. Glover, RFID Essentials, O'Reilly Media, Inc., Sebastopol, California, USA 2006

As shown in figure no.2, the manufacturers, logistics centre and retailers maintain local EPCIS instances. The local EPCIS instances are tasked to maintain the EPC tracking information generated by the component, and they also help interface with other EPCIS instances that maintain relevant and desired EPC information. An EPCIS server can host, as well as facilitate access to, serialized product information generated by EPC-tagged products. This means a logistics centre's EPCIS server can be shaped in such way that it can interface with a manufacturer's EPCIS server to access proper data. ${ }^{7}$

To gain the maximum benefits from RFID in cooperation between logistics centre, manufactures and retailers, various business partners worldwide need to use common tags, readers

\footnotetext{
${ }^{6}$ S. Li, J. K. Visich, B. M. Khumawala, C. Zhang, Radio frequency identification technology: applications, technical challenges and strategies, Sensor Review 26/3 (2006) 193-202 Emerald Group Publishing Limited [ISSN 0260-2288] p. 195

${ }^{7}$ H. Bhatt, B. Glover, RFID Essentials, O’Reilly Media, Inc., Sebastopol, California, USA 2006
} 
and frequencies so that they can be used beyond the confines of one company's walls. Successful implementation of an RFID system will require a good strategic plan as well as high-quality management of cooperation between all business partners. One of possible ways of to achieve success in RFID field is to prepare excellent project. The final result should better and better collaboration between manufactures and logistics centers.

\section{References}

1. Abernathy F. H., Dunlop J. T., Hammond J. H., Weil D., Retailing and supply chains in the information age, Technology in Society 22 (2000) 5-31, Elsevier

2. Abt S., Zarzadzanie logistyczne w przedsiebiorstwie, PWE, Warszawa 1998

3. Attaran M., Collaborative computing: a new management strategy for increasing productivity and building a better business, VOL. 8 NO. 6 2007, pp. 387-393, Emerald Group Publishing Limited, ISSN 1751-5637 BUSINESS STRATEGY SERIES

4. Bhatt H., Glover B., RFID Essentials, O'Reilly Media, Inc., Sebastopol, California, USA 2006

5. Li S., Visich J. K., Khumawala B. M., Zhang C., Radio frequency identification technology: applications, technical challenges and strategies, Sensor Review 26/3 (2006) 193-202 Emerald Group Publishing Limited [ISSN 0260-2288]

6. Sweeney P. J., RFID for Dummies, Wiley Publishing, Inc., Indianapolis, Indiana, USA, 2005

7. Thiesse F. RFID, privacy and the perception of risk: A strategic framework, Journal o Strategic Information Systems 16 (2007) 214-232,

8. Wu N.C., Nystrom M.A., Lin T.R., Yu H.C., Challenges to global RFID adoption Technovation 26 (2006) 1317-1323, p. 1317 